\title{
Pengaruh Kompetensi Konselor Terhadap Pelayanan Penanganan Korban Kekerasan Dalam Rumah Tangga Pada P3KC
}

\author{
Mahfudoh ${ }^{1}$ Dian Handayani²
}

\section{ABSTRAK}

Penelitian ini bertujuan untuk mengetahui pengaruh kompetensi konselor pada Pusat Pelayanan dan Perlindungan Keluarga Cilegon (P3KC) dalam memberikan pelayanan penanganan kepada korban Kekerasan Dalam Rumah Tangga (KDRT). Dalam Penelitian ini penulis menggunakan metode deskriptif analisis dengan pendekatan kuantitatif, yang kemudian diolah dan dianalisis untuk diambil kesimpulan, maka analisis kuantitatif dilakukan dengan cara mengkuantitatifkan data-data penelitian ke dalam bentuk angka-angka dengan menggunakan skala likert. Populasi dalam penelitian ini adalah korban kekerasan yang melapor ke Pusat Pelayanan dan Perlindungan Keluarga Cilegon (P3KC) di tahun 2017 yang berjumlah 139 korban/klien, dan kasus kekerasan dalam rumah tangga berjumlah 71 korban/klien, tetapi hanya mengambil 50 responden korban kekerasan dalam rumah tangga yang telah diselesaikan permasalahannya oleh Pusat Pelayanan dan Perlindungan Keluarga Cilegon (P3KC). Metode pengambilan sampel yang digunakan adalah Stratified random sampling. Metode analisis yang digunakan adalah adalah analisis regresi linier sederhana. Dengan menggunakan analisa regresi, maka hasil penelitian diperoleh didapatkan nilai thitung sebesar 8,191, selanjutnya nilai ini akan dibandingkan dengan menggunakan batas signifikan 0,05 dan hasil perhitungan yang didapat adalah dk $\mathrm{n}-2(50-2=48)$, maka didapat tabel sebesar 1,677. Didapat thitung lebih besar dari tabel $(8,191>1,677)$, maka Ha diterima, $\mathrm{H}_{0}$ ditolak, artinya terdapat pengaruh yang signifikan dari variabel Kompetensi Konselor $(X)$ terhadap Pelayanan Penanganan $(Y)$. Berdasarkan hasil uji koefisien determinasi $X$ kontribusi hubungan antara variabel Kompetensi Konselor $(X)$ terhadap variabel Pelayanan Penanganan ( $\mathrm{Y}$ ) didapat nilai $\mathrm{R}$ square sebesar $59 \%$ artinya kontribusi hubungan antara variabel Kompetensi Konselor $(X)$ terhadap variabel Pelayanan Penanganan $(\mathrm{Y})$ dan $41 \%$ sisanya dipengaruhi oleh faktor lain yang tidak diteliti oleh peneliti.

Kata Kunci: kompetensi konselor, pelayanan penanganan

\section{ABSTRACT}

This study aims to determine the effect of counselor competence at the Cilegon Family Protection and Service Center (P3KC) in providing treatment services to victims of Domestic Violence (Domestic Violence). This study the author uses descriptive analysis method with a quantitative approach, which is then processed and analyzed for

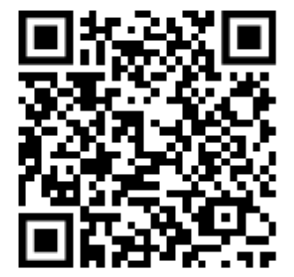

Program Studi Manajemen Sekolah Tinggi Ilmu Ekonomi Al-Khairiyah, Jalan K.H. Ahmad Dahlan No.15, Citangkil, Kota Cilegon, Banten 42441 Indonesia

EMail

mahfudoh774@gmail.com

Submitted : Juni 2019 Accepted : Juli 2019
JAS-PT

JURNAL ANALISIS SISTEM PENDIDIKAN TINGG

ISSN 2580 - 5339

eISSN $2620-5718$

Volume 3

Nomor 1

JULI 2019

Hal 1 - 12

FORUM DOSEN INDONESIA 
conclusions, then quantitative analysis is done by quantifying research data into numbers using a Likert scale. The population in this study were victims of violence who reported to the Cilegon Family Protection and Service Center (P3KC) in 2017 totaling 139 victims / clients, and cases of domestic violence amounted to 71 victims / clients, but only took 50 respondents victims of domestic violence stairs that have been resolved by the Cilegon Family Service and Protection Center (P3KC). The sampling method used is Stratified random sampling. The analytical method used is simple linear regression analysis. By using regression analysis, the results obtained obtained tcount of 8.119 , then this value will be compared using a significant limit of 0.05 and the calculation results obtained are $d k n-2(50-2=48)$, then obtained ttable of 1.677 . Obtained $t$ count is greater than $t$ table $(8,191>1,677)$, then $\mathrm{Ha}$ is accepted, $\mathrm{HO}$ is rejected, meaning that there is a significant influence from Counselor Competency $(X)$ variable on Handling Service $(Y)$. Based on the test results of the determination coefficient $X$, the contribution of the relationship between the Counselor Competency variable $(X)$ to the Handling Service $(Y)$ variable is $R$ square value of $59 \%$, which means the contribution of the relationship between Counselor Competency $(X)$ variables to Handling Service $(Y)$ and the remaining $41 \%$ influenced by other factors not examined by researchers

Keywords: counselor competence, handling service

\section{PENDAHULUAN}

Kekerasan terhadap perempuan dan anak masih sering kita jumpai disekitar kita, dan ini merupakan ancaman terus menerus bagi perempuan dimanapun berada seperti halnya tindakan yang menghambat tercapainya kesetaraan, kemajuan dan perdamaian. Dari kacamata hak asasi manusia, fenomena ini merupakan pelanggaran, sebuah kejahatan terhadap kemanusiaan.Akar masalah dari kekerasan terhadap perempuan adalah ketimpangan relasi kuasa antara pelaku dan korban. Nilai budaya yang meletakkan posisi perempuan pada posisi sub-ordinasi dan marjinal yang mengakibatkan kekerasan terhadap perempuan terjadi.

Korban kekerasan dalam rumah tangga (KDRT) harus mendapat perlindungan dari pemerintah di tingkat pusat maupun di tingkat pemerintah Daerah, dan atau dari masyarakat agar terhindar dan terbebas dari kekerasan atau ancaman kekerasan, penyiksaan atau perlakuan yang merendahkan derajat dan martabat kemanusiaan. Salah satu langkah besar dan sangat berharga bagi masyarakat adalah upaya pemerintah dalam hal perlindungan perempuan yaitu terbitnya Undang-Undang No. 23 Tahun 2004 tentang Penghapusan Kekerasan Dalam Rumah Tangga (PKDRT) Pengertian Kekerasan Dalam Rumah Tangga menurut pasal 1 butir 1 Undang - undang Nomor 23 Tahun 2004 adalah setiap perbuatan terhadap seseorang terutama perempuan, yang berakibat timbulnya kesengsaraan atas penderitaan secara fisik, seksual, psikologis dan/atau penelantaran rumah tangga termasuk ancaman untuk melakukan perbuatan, pemaksaan, atau perampasan kemerdekaan seseorang secara melawan hukum dalam lingkungan rumah tangga.

JAS-PT

JURNAL ANALISIS SISTEM PENDIDIKAN TING ISSN $2580-5339$ eISSN $2620-5718$

Volume 3

Nomor 1

JULI 2019

Hal $1-12$

FORUM DOSEN INDONESIA

Tujuan dan Kegunaan penelitian ini antara lain :

1. Bagi Instansi, Sebagai bahan evaluasi tentang permasalahan dan hambatan yang dihadapi agar dapat meningkatkan pelayanan penanganan penyelesaian kasus KDRT yang terjadi terhadap masyarakat di Kota Cilegon 
2. Agar dapat mengetahui bahwa di Kota Cilegon terdapat Pusat Pelayanan dan Perlindungan Keluarga Cilegon (P3KC)dan mengetahui pelayanan apa saja yang diberikan bagi korban KDRT, sehingga dapat melaporkan ke P3KC dan dapat meminimalisir angka kekerasan dalam rumah tangga yang terjadi di Kota Cilegon.

\section{TINJAUAN PUSTAKA}

\section{Kekerasan Dalam Rumah Tangga}

Bentuk-bentuk kekerasan dalam lingkup rumah tangga diantaranya yaitu:

1. Kekerasan Fisik : Setiap perbuatan yang mengakibatkan rasa sakit, jatuh sakit atau luka berat seperti dipukul, ditampar, dan lain sebagainya.

2. Kekerasan Psikis : Setiap perbuatan yang mengakibatkan ketakutan, hilangnya rasa percaya diri, hilangnya kemampuan untuk bertindak, rasa tidak berdaya, dan atau penderitaan psikis berat pada seseorang.

3. Kekerasan Seksual : Setiap perbuatan yang berupa pemaksaaan hubungan seksual dengan cara tidak wajar dan atau tidak disukai, pemaksaan hubungan seksual dengan orang lain untuk tujuan komersial dan atau tujuan tertentu.

4. Kekerasan Ekonomi atau Penelantaran Rumah Tangga : Setiap perbuatan yang mengakibatkan ketergantungan ekonomi dengan cara membatasi dan atau melarang untuk bekerja yang layak di dalam atau di luar rumah sehingga korban berada di bawah kendali orang tersebut

\section{Kompetensi}

Kompetensi berdasarkan Undang - Undang Nomor 13 Tahun 2003 tentang Ketenagakerjaan, menyatakan bahwa kompetensi adalah kemampuan kerja setiap individu yang mencakup aspek pengetahuan, keterampilan dan sikap kerja yang sesuai dengan standar yang ditetapkan.

(RM. Pane : 2016) tentang Kompetensi Kepribadian Konselor Dalam Pelaksanaan Bimbingan Dan Konseling Islam menyimpulkan bahwa Kompetensi dan keahlian sangat dibutuhkan untuk menjadi konselor efektif dan akan terus meningkat, sejalan dengan perkembangan konseling. Namun ada beberapa kompetensi dan kemampuan dasar yang harus dimiliki semua konselor agar dapat bekerja dan memberikan pelayanan yang efektif,salah satunya kepribadian konselor. Beberapa kepribadian yang perlu dimiliki oleh seorang konselor adalah:

1. Empati. Empati adalah kemampuan seseorang untuk merasakan secara tepat apa yang dirasakan dan dialami oleh orang lain mengkomunikasikan persepsinya. Orang yang memiliki tingkat empati tinggi akan menampakkan sikap bantuannya yang nyata dan berarti dalam hubungannya dengan orang lain, sementara mereka yang rendah empatinya menunjukan sikap yang secara nyata dan berarti merusak hubungan antar pribadi.Lebih lanjut Eisenberg and Strayer mengatakan bahwasalah satu yang paling penting dan mendasar pada proses empati adalah pemahaman adanyaperbedaan antara individu (perceiver) dan orang lain.

2. Respek. Respek menunjukan secara tak langsung bahwa konselor menghargai martabat dan nilai klien sebagai manusia. Hal ini mengandung arti juga bahwa konselor menerima kenyataan. Setiap klien menerima hak untuk memilih sendiri, memiliki kebebasan, kemauan, dan mampu membuat keputusannya sendiri. Hal ini sesuai dengan yang diungkapkan oleh Patterson bahwa respek itu sikap mengakui, menghargai dan menerima klien apa adanya, tidak membodoh-bodohkan klien,

JAS-PT

JURNAL ANALISIS SISTEM PENDIDIKAN TINGG

ISSN $2580-5339$

eISSN $2620-5718$

Volume 3

Nomor 1

JULI 2019

Hal $13-20$

FORUM DOSEN INDONESIA 
terbuka menerima pendapat dan pandangan klien tanpa menilai atau mencela, terbuka untuk berkomunikasi dengan klien.

3. Kemampuan. Kemampuan berarti memiliki kesanggupan, kecakapan dan kekuatan untuk melakukan sesuatu. Dari pengertian tersebut dapat diketahui bahwa ketika seseorang melakukan berbagai tugas dalam satu pekerjaan dan dinilai oleh orang lain, maka dapat diketahui kemampuan yang dimiliki orang tersebut. Kesanggupan sebagai suatu kekuatan yang dinamis dan magnetis dari kompetensi pribadi konselor. Konselor yang memiliki sifat potensi ini selalu menampakkan kekuatannya dalam penampilan pribadinya.

4. Kesiapan. Slameto menjelaskan bahwa kesiapan adalah keseluruhan kondisi seseorang atau individu yang membuatnya siap untuk memberikan respon atau jawaban di dalam cara tertentu terhadap suatu situasi dan kondisi yang dihadapi.

5. Aktualisasi Diri. Menurut Asmadi aktualisasi diri merupakan kemampuan seseorang untuk mengatur diri sendiri sehingga bebas dari berbagai tekanan baik yang berasal dari dalam diri maupun dari luar diri. Kemampuan seseorang untuk mengatur diri sendiri dari tekanan internal dan eksternal dalam pengaktualisasian dirinya menunjukkan bahwa orang tersebut telah mencapai kematangan diri.Dengan demikian dapat dipahami bahwa aktualisasi diri merupakan suatu proses menjadi diri sendiri, tidak meniru dan tidak terkontaminasi dengan dialek, gaya atau sikap orang lain dengan cara mengembangkan sifat-sifat serta potensi individu sesuai dengan keunikannya yang ada untuk menjadi kepribadian yang utuh.

\section{Pelayanan Konselor}

Kamus Besar Bahasa Indonesia (KBBI), menyatakan bahwa pelayanan adalah sebagai suatu usaha untuk membantu menyiapkan atau mengurus apa yang diperlukan orang lain. Sedangkan menurut Moenir (2010:26) pelayanan adalah kegiatan yang dilakukan oleh seseorang atau sekelompok orang dengan landasan faktor materi melalui sistem, prosedur dan metode tertentu dalam rangka usaha memenuhi kepentingan orang lain sesuai dengan haknya.

Berdasarkan Undang-Undang No. 25 Tahun 2009 Tentang Pelayanan Publik terlihat bahwa pelayanan merupakan tugas utama yang hakiki dari sosok aparatur sebagai abdi Negara dan abdi masyarakat. Tugas aparatur sebagai pelayan harus lebih diutamakan, terutama yang berkaitan dengan mendahulukan kepentingan umum, mempermudah urusan masyarakat, mempersingkat waktu proses pelaksanaan urusan publik dan memberikan kepuasan publik. Pelayanan publik pada dasarnya menyangkut aspek kehidupan yang sangat luas.

Pelayanan bagi perempuan korban kejahatan kekerasan di kepolisian seperti Polda, Polresta dan Polres adalah dengan menyediakan Ruang Pelayanan Khusus yang di perkuat dengan keluarnya Undang- Undang No. 23 Tahun 2004 Tentang Penghapusan Kekerasan Dalam Rumah Tangga, Tepatnya pada Pasal 13, yakni: "Bentuk penyelenggaraan pelayanan terhadap korban, pemerintah dan pemerintah daerah sesuai dengan fungsidan tugas masing-masing dapat melakukan upaya:

JAS-PT

JURNAL ANALISIS SISTEM PENDIDIKAN TINGG ISSN $2580-5339$ eISSN $2620-5718$ Volume 3

Nomor 1

JULI 2019

Hal $13-20$ a. Penyediaan aparat, tenaga kesehatan, pekerja sosial, dan pembimbing rohani;

b. Penyediaan ruang pelayanan khusus di kantor kepolisian;

c. Pembuatan dan pengembangan system dan mekanisme kerjasama program pelayanan yang melibatkan pihak yang mudah diakses oleh korban;

d. Memberikan perlindungan bagi pendamping, saksi, keluarga dan teman korban." 
Dalam bidang layanan bagi perempuan dan anak korban kekerasan ada yang disebut dengan Standar Operasional Prosedur (SOP). SOP merupakan langkah-langkah standar yang harus dilakukan dalam memberikan pelayanan, yang meliputi 5 jenis pelayanan, yaitu;

1. Penanganan kasus,

2. Pelayanan kesehatan,

3. Rehabilitasi sosial,

4. Penegakan dan bantuan hukum,

5. Pemulangan dan reintegrasi sosial.

\section{Kerangka Penelitian}

\begin{tabular}{|c|c|}
\hline Kompetensi & Pelavanan \\
\hline $\begin{array}{l}\text { 1. } \text { Empati } \\
\text { 2. Respek } \\
\text { 3. Kemampuan } \\
\text { 4. Kesiapan } \\
\text { 5. Aktualisasi diri } \\
\text { Sumber : } \\
\text { Penelitian RM. Pane } \\
\text { (2016) }\end{array}$ & $\begin{array}{ll}\text { 1. } & \text { Penanganan } \\
\text { kasus, } \\
\text { 2. }\end{array}$ \\
\hline
\end{tabular}

\section{Gambar 1 Paradigma Penelitian}

\section{METODOLOGI PENELITIAN}

Metode penelitian yang digunakan adalah deskriptif analisis dengan pendekatan kuantitatif, yang kemudian diolah dan dianalisis untuk diambil kesimpulan, maka analisis kuantitatif dilakukan dengan cara mengkuantitatifkan data-data penelitian ke dalam bentuk angka-angka dengan menggunakan skala likert. Populasi dalam penelitian ini adalah korban kekerasan yang melapor ke Pusat Pelayanan dan Perlindungan Keluarga Cilegon (P3KC) di tahun 2017 yang berjumlah 139 korban/klien, dan kasus kekerasan dalam rumah tangga berjumlah 71 korban/klien, tetapi hanya mengambil 50 responden korban kekerasan dalam rumah tangga yang telah diselesaikan permasalahannya oleh Pusat Pelayanan dan Perlindungan Keluarga Cilegon (P3KC). Metode pengambilan sampel yang digunakan adalah Stratified random sampling.

Metode analisis yang digunakan adalah adalah 1) Deskripsi Data, 2) Uji Instrumen, 3) Uji Hipotesis Penelitian dengan menggunakan Korelasi Product Moment, 4) Uji Koefisien Determinan dan 5) Regresi Linier.

\section{Hipotesis penelitian}

Hipotesis berarti dugaan atau jawaban sementara terhadap suatu permasalahan penelitian. Berdasarkan landasan teori dan kerangka pemikiran "Diduga Terdapat Pengaruh Kompetensi Terhadap Pelayanan Penanganan Korban Kekerasan Dalam Rumah Tangga (KDRT) pada Pusat Pelayanan dan Perlindungan Keluarga Cilegon (P3KC)".

JAS-PT

JURNAL ANALISIS SISTEM PENDIDIKAN TINGG ISSN $2580-5339$ eISSN $2620-5718$

Volume 3

Nomor 1

JULI 2019

Hal $13-20$

FORUM DOSEN INDONESIA 


\section{HASIL DAN PEMBAHASAN}

Setelah melakukan analisis data, diperoleh hasil bahwa semua butir pernyataan adalah valid. Variabel independen yang diuji secara individual yang dominan dalam mempengaruhi Pelayanan Penanganan $(\mathrm{Y})$ adalah Kompetensi Konselor $(\mathrm{X})$ dengan nilai rata-rata tanggapan responden sebesar 434,7 .

Berikut ini adalah beberapa hasil analisis data yang telah diteliti :

1. Uji validitas menunjukkan bahwa $r_{\text {hitung }}$ dari beberapa variabel lebih besar dari $r_{\text {tabel }}$ sebesar 0,279 yang berarti bahwa semua indikator adalah valid.

2. Uji reliabilitas menunjukkan bahwa Cronbach's Alpha dari setiap variabel lebih besar dari $r$ standar 0,60 yang berarti bahwa kuesioner yang merupakan semua indikator dari variabel tersebut adalah reliabel.

3. Uji Product moment menunjukkan nilai koefisien korelasi $\mathrm{R}$ 0,764., bahwa nilai koefisien korelasi variabel kompetensi konselor $(X)$ masuk pada interval koefisien tingkat hubungan sangat kuat, maka dapat diartikan bahwa terdapat korelasi yang sangat kuat antara variabel Kompetensi Konselor $(X)$ dan variabel Pelayanan Penanganan $(\mathrm{Y})$.

4. Uji Koefisien Determinan menunjukkan bahwa, kontribusi hubungan antara variabel Kompetensi Konselor (X) terhadap variabel Pelayanan Penanganan ( $\mathrm{Y}$ ) sebesar 59\% dan $41 \%$ sisanya dipengaruhi oleh faktor lain yang tidak diteliti oleh peneliti.

5. Uji t menunjukkan bahwa, variabel Kompetensi Pegawai $(X)$, memiliki pengaruh yang signifikan terhadapPelayanan Penanganan $(Y)$. Dengan thitung lebih besar dari tabel $(8,191>1,677)$, artinya terdapat pengaruh yang signifikan dari variabel Kompetensi Konselor $(\mathrm{X})$ terhadap Pelayanan Penanganan $(\mathrm{Y})$.

6. Uji Regresi Linier sederhana menunjukkan koefisien konstanta sebesar 13,785 data tersebut menyatakan bahwa jika variabel Kompetensi Konselor bernilai 0 atau konstan, dan Kompetensi Konselor memiliki nilai koefisien regresi sebesar 0,644. Data tersebut menyatakan bahwa jika Kompetensi Konselor mengalami peningkatan, maka Pelayanan Penanganan akan naik sebesar 0,644.

Dari hasil pembahasan di atas dapat disimpulkan hipotesis dari penelitian ini adalah didapat thitung lebih besar dari tabel $(8,191>1,677)$, maka Ha diterima, $\mathrm{H}_{0}$ ditolak, artinya terdapat pengaruh yang signifikan dari variabel Kompetensi Konselor $(X)$ terhadap Pelayanan Penanganan (Y).

\section{PENUTUP}

\section{Simpulan}

Berapa kesimpulan yang dapat ditarik dari hasil penelitian ini adalah sebagai berikut:

1. Kompetensi Konselor pada Pusat Pelayanan dan Perlindungan Keluarga Cilegon (P3KC) kepada korban Kekerasan Dalam Rumah Tangga (KDRT) untuk variabel kompetensi konselor diperoleh hasil rata-rata 434,7 dari semua nilai kuesioner, dan termasuk dalam kategori sangat baik.

JAS-PT

JURNAL ANALISIS SISTEM PENDIDIKAN TINGG ISSN $2580-5339$ eISSN $2620-5718$ Volume 3

Nomor 1

JULI 2019

Hal $13-20$

FORUM DOSEN INDONESIA
2. Untuk pelaksanaan Pelayanan Penanganan berdasarkan hasil yang diperoleh ratarata 452,5dan semua nilai kuesioner yang termasuk dalam kategori sangat baik.

3. Dalam penelitian ini didapat bahwa, Variabel Kompetensi Pegawai $(X)$, memiliki pengaruh yang signifikan terhadap Pelayanan Penanganan $(Y)$. Dengan thitung lebih besar dari tabel $(8,191>1,677)$, artinya terdapat pengaruh yang signifikan dari variabel Kompetensi Konselor $(X)$ terhadap Pelayanan Penanganan $(Y)$. 


\section{Saran}

Berdasarkan data yang telah diolah terdapat tanggapan negatif dari pernyataan yang telah isi oleh responden, maka penulis memberikan saran-saran sebagai berikut :

1. Berdasarkan hasil penelitian variabel Kompetensi Konselor $(X)$ pada Pusat Pelayanan dan Perlindungan Keluarga Cilegon (P3KC), terdapat nilai terkecil pada pernyataan Konselor bekerja secara profesional. Keadaan ini terjadi karena banyaknya korban yang melapor dan membutuhkan pelayanan tetapi jumlah konselornya terbatas dan harus diselesaikan segera. Untuk itu diharapkan Pemerintah Kota Cilegon dapat menambahpersonil konselor agar melakukan pelayanan kepada masyarakat Kota Cilegon.

2. Pada hasil penelitian variabel Pelayanan Penanganan $(\mathrm{Y})$, terdapat nilai terkecil pada pernyataan pelayanan dalam penanganan korban dilakukan dengan cepat dan cermat. Keadaan ini terjadi dikarenakan perbandingan antara korban yang mengadu dengan personil konselor yang ada sangat jauh, di tahun 2017 klien berjumlah 139 dan tenaga konselor berjumlah 3 orang. Jadi 139 klien hanya ditangani oleh 3 orang konselor. Untuk itulah Pusat Pelayanan dan Perlindungan Keluarga Cilegon (P3KC) harus lebih melakukan peningkatan pelayanannya agar klien dapat membantu dengan Optimal.

3. Semakin meningkatnya kasus Kekerasan Dalam Rumah Tangga (KDRT) setiap tahunnya sebaiknya lebih banyak melakukan sosialisasi untuk pencegahan agar meminimalisir terjadinya kasus Kekerasan Dalam Rumah Tangga (KDRT).

\section{DAFTAR PUSTAKA}

Assauri, Sofjan. 1999. Manajemen Pemasaran: Dasar, Konsep dan Strategi, PT. Raja Grafindo Persada, Jakarta.

Asmadi, Teknik Prosedural Keperawatan Konsep dan Aplikasi Kebutuhan Dasar, Salemba Medika, Jakarta, 2008

Boediono, B , 2003. Pelayanan Prima Perpajakan. PT. Rineka Cipta, Jakarta

Bella Pertiwi, 2016, Pengaruh Kompetensi Terhadap Kinerja Pegawai Tata Usaha Pusat Penelitian Biologi Lembaga IImu Pengetahuan Indonesia, Universitas Pertanian Bogor, Bogor.

Faiza Nurmasitha, Abdul Hakim, Wima Yudo Prasetyo, Jurnal "Pengaruh Kompetensi Pegawai dan Lingkungan Kerja Terhadap Kualitas Pelayanan" (studi Pada Dinas Kependudukan dan Catatan Sipil Kabupaten Sidoarjo).

Masri Singarimbun, Sofian Effendi, 1987. Metode Penelitian Survai, PT. Pustaka Lembaga Penelitian, Pendidikan dan Penerangan Ekonomi dan Sosial. Yogyakarta.

Moenir, H.A.S. 2002. Manajemen Pelayanan Umum di Indonesia, Bumi Aksara. Jakarta.

Ni Made Arie Sulistyawati dan Ni Ketut Seminari, 2015, Pengaruh Kualitas Pelayanan Terhadap Kepuasan Pelanggan Restoran Indus Ubud Gianyar, Bali.

Peraturan Menteri Pemberdayaan Perempuan dan Perlindungan Anak RI Nomor 01 tahun 2010 tentang Standar Pelayanan Minimal (SPM) Bidang layanan terpadu bagi perempuan dan anak korban kekerasan, 2010, Jakarta.

JAS-PT

JURNAL ANALISIS SISTEM PENDIDIKAN TINGG

ISSN $2580-5339$

eISSN $2620-5718$

Volume 3

Nomor 1

JULI 2019

Hal $13-20$

FORUM DOSEN INDONESIA 
Prosedur Standar Operasional Pelaksanaan Standar Pelayanan Minimal (SPM) Bidang layanan terpadu bagi perempuan dan anak korban kekerasan, 2010, Jakarta.

Peraturan Kepala Badan Kepegawaian Negara Nomor 8 Tahun 2013.

Ratminto dan Atik Septi Winarsih, 2005, Manajemen Pelayanan, Pustaka Pelajar. Yogyakarta.

Riem Malini Pane, 2016, Kompetensi Kepribadian Konselor Dalam Pelaksanaan Bimbingan Dan Konseling Islam.

Sianipar, 1998, Manajemen Pelayanan Masyarakat. LAN. Jakarta.

Sugiyono, 2004, Metode Penelitian Bisnis, Alfabeta. Bandung.

Sudjana, 2006, Metode Statistika, Penerbit Tarsito, Bandung.

Tjiptono, Fandy, 2000. Manajemen Jasa, Edisi Kedua, Andy Offset. Jakarta.

Undang - undang RI Nomor 23 Tahun 2004 tentang Penghapusan Kekerasan Dalam Rumah Tangga (KDRT). Kementerian Negara Pemberdayaan Perempuan dan Perlindungan Anak RI Deputi Bidang Perlindungan Perempuan. Cetakan Kelima 2008. Jakarta.

Undang-Undang No. 25 Tahun 2009 tentang Pelayanan Publik diunduh pada 12 April 2018 dari http://hukumonline.com.

Wibowo. 2007, Manajemen Kinerja. PT. Raja Grafindo Persada. Jakarta.

Yulia Nova, 2017, Penelitian tentang Penyelenggaraan Pelayanan Terhadap Perempuan Dan Anak Kasus Korban Kejahatan Kekerasan Di Polres Kabupaten Padang Pariaman. Padang.

\section{JAS-PT}

JURNAL ANALISIS SISTEM PENDIDIKAN TINGG

ISSN $2580-5339$

eISSN $2620-5718$

Volume 3

Nomor 1

JULI 2019

Hal $13-20$

FORUM DOSEN INDONESIA 